\title{
OPTIMAL ORAL ANTICOAGULANT THERAPY IN PATIENTS WITH NONRHEUMATIC ATRIAL FIBRILLATION AND REGENT CEREBRAL ISCHEMIA
}

\author{
The European Atrial Fibrillation Trial Study Group*
}

\begin{abstract}
Background. A number of studies have demonstrated the efficacy of oral anticoagulant therapy in reducing the risk of stroke and systemic embolism in patients with nonrheumatic atrial fibrillation. However, both the targeted and the actual levels of anticoagulation differed widely among the studies, and a number of studies failed to report standardized prothrombin-time ratios as international normalized ratios (INRs). We therefore performed an analysis to determine the intensity of oral anticoagulant therapy in nonrheumatic atrial fibrillation that provides the best balance between the prevention of thromboembolism and the occurrence of bleeding complications.

Methods. We calculated INR-specific incidence rates for both ischemic and major hemorrhagic events occurring in 214 patients who received anticoagulant therapy in
\end{abstract}

$\mathrm{T}$ HE efficacy of oral anticoagulant therapy in reducing the risk of stroke and systemic embolism has been demonstrated for both primary and secondary prevention in patients with nonrheumatic atrial fibrillation. Reductions in the risk of thromboembolic events (usually defined as ischemic stroke and systemic embolism) range from 37 to 86 percent, but major bleeding complications occur at rates of 5 to 28 per 1000 patientyears. ${ }^{1-7}$ However, the targeted therapeutic ranges, as well as the levels of anticoagulant control actually obtained, differed widely among studies. In primaryprevention trials, for example, 8 to 40 percent of the international normalized ratios (INRs) fell below the targeted range, and 1 to 17 percent exceeded the upper limit. ${ }^{1-6}$ Only a few studies originally recorded prothrombin-time ratios in INR equivalents to account for differences in preparations of thromboplastin. ${ }^{8}$ It has therefore been suggested that the intention-to-treat analyses sometimes used ${ }^{7}$ may have led to incomplete or misleading conclusions. ${ }^{9}$ Additional analyses are required to determine what intensity of oral anticoagulant therapy in patients with nonrheumatic atrial fibrillation offers the best balance between the prevention of thromboembolism and the occurrence of bleeding complications.

Using a recently proposed method to determine the optimal intensity of oral anticoagulant therapy, ${ }^{10}$ we calculated INR-specific incidence rates for ischemic as well as major hemorrhagic events occurring in the an-

Address reprint requests to Dr. Peter J. Koudstaal at the Department of Neurology, University Hospital Rotterdam Dijkzigt, 40 Dr. Molewaterplein, 3015 GD Rotterdam, the Netherlands.

Supported by a grant (87.048) from the Netherlands Heart Foundation and by grants from Bayer Germany, the U.K. Stroke Association, University Hospital Utrecht, and University Hospital Rotterdam.

*The centers and investigators collaborating in the European Atrial Fibrillation Trial are listed in the Appendix. This article was prepared by Jeanette C. van Latum, M.D., and Peter J. Koudstaal, M.D., University Hospital Rotterdam Dijkzigt; and Jan van Gijn, M.D., L. Jaap Kappelle, M.D., and Ale Algra, M.D., University Hospital Utrecht — both in the Netherlands. Dr. Koudstaal, as principal investigator, assumes full responsibility for the overall content and integrity of the article. the European Atrial Fibrillation Trial, a secondary-prevention trial in patients with nonrheumatic atrial fibrillation and a recent episode of minor cerebral ischemia.

Results. The optimal intensity of anticoagulation was found to lie between an INR of 2.0 and an INR of 3.9. No treatment effect was apparent with anticoagulation below an INR of 2.0. The rate of thromboembolic events was lowest at INRs from 2.0 to 3.9, and most major bleeding complications occurred with treatment at intensities with INRs of 5.0 or above.

Conclusions. To achieve optimal levels of anticoagulation with the lowest risk in patients with atrial fibrillation and a recent episode of cerebral ischemia, the target value for the INR should be set at 3.0, and values below 2.0 and above 5.0 should be avoided. (N Engl J Med 1995; 333:5-10.)

ticoagulation cohort of the European Atrial Fibrillation Trial, a secondary-prevention trial in patients with nonrheumatic atrial fibrillation and a recent transient ischemic attack or minor ischemic stroke. ${ }^{7}$

\section{Methods}

\section{Patients}

The study group consisted of patients in the European Atrial Fibrillation Trial who had been randomly assigned to oral anticoagulant therapy. This study was a randomized, multicenter clinical trial that aimed to assess the therapeutic efficacy and safety of oral anticoagulants and aspirin for the prevention of vascular events in patients with nonrheumatic atrial fibrillation and a recent minor cerebral ischemic event. Patients eligible for treatment with oral anticoagulants were randomly assigned to open anticoagulant treatment (INR, 2.5 to 3.9) or double-blind treatment with either aspirin (300 mg per day) or placebo. Informed consent was obtained from all study patients. The study protocol was reviewed and approved by the institutional review boards of all participating hospitals.

\section{Anticoagulant Control}

The choice of anticoagulant was left to the discretion of the physician and depended largely on that physician's personal experience with the various agents and on their availability. Most often, physicians prescribed relatively short-acting preparations of acenocoumarol, but warfarin and fenprocoumon were also used. The dose of anticoagulant was adjusted on the basis of the patient's prothrombin time. To accommodate variations in the composition and responsiveness of the thromboplastins and in the methods needed to measure the prothrombin time, all the centers were asked to use only calibrated commercial preparations. This would allow prothrombin-time values to be reported in INR equivalents. ${ }^{11,12}$ All the centers used well-known, standardized thromboplastins. The collaborating investigators were urged to use conversion tables available from the laboratories involved, and these tables were checked during site visits. The INRs were to be maintained at a target value of 3.0 (range, 2.5 to 3.9 ). ${ }^{13,14}$ The prothrombin time had to be monitored at least once a month, and the resulting values were reported to the study office every four months, when the patient came for a follow-up visit. When the intensity of anticoagulation consistently fell below the proposed range, the centers were notified by the study office.

\section{Calculation of INR-Specific Event Rates}

The data required to calculate INR-specific event rates included both information on the occurrence of events (the numerator) and 
the time the patient spent in each range of anticoagulation intensity (the denominator).

\section{Definitions of Events}

To assess the optimal intensity of anticoagulation, we classified the outcome events as much as possible as ischemic or hemorrhagic complications. The primary measure of outcome in the trial was the composite event of death from cardiovascular causes, nonfatal stroke (including intracranial hemorrhage), nonfatal myocardial infarction, or systemic embolism, whichever occurred first. Death from cardiovascular causes included sudden death (in which the death was seen by an eyewitness, with a reliable observation of the time between the onset of symptoms and death, or the patient was found dead) or death from stroke, myocardial infarction, congestive heart failure, systemic embolism, noncerebral bleeding, or other cardiovascular causes (including pulmonary embolism and peripheral vascular disease). Except for documented extracerebral hemorrhages, all these events were classified as ischemic.

The diagnosis of nonfatal stroke required the finding of a focal neurologic deficit that persisted for more than 24 hours. Computed tomographic (CT) scans performed at the time of the outcome event were centrally audited by physicians who were unaware of the assigned treatment. On the basis of these scans, the distinction between ischemic stroke, ischemic stroke with hemorrhagic transformation, and primary intracerebral hemorrhage was made. The diagnosis of systemic embolism was defined clinically as an abrupt vascular insufficiency of the limbs or internal organs associated with clinical or radiologic evidence of arterial occlusion, in the absence of previous obstructive disease; it did not include pulmonary embolism. Myocardial infarction had to be documented by at least two of the following characteristics: a history of chest discomfort, specific cardiac-enzyme levels more than twice the upper limit of normal, and the development of $Q$ waves on a standard 12-lead electrocardiogram.

The occurrence of bleeding complications was recorded at each follow-up visit for each patient. Hemorrhagic episodes were classified according to severity. Fatal bleeding complications had to be documented by convincing clinical evidence or autopsy. Nonfatal bleeding complications were considered to be major if admission to the hospital and at least one transfusion or surgery were necessary, or if the complication caused a permanent increase in disability. Nosebleeds, bruising, hematemesis, and hematuria were considered to be minor if no transfusion or operative intervention was required. All events were classified independently by at least three members of the auditing committee for outcome events, after the medical records had been summarized and edited to ensure that the reviewers remained unaware of the assigned treatment. Differences of opinion were discussed in the Executive Committee, which was also blinded, and were decided by a majority vote.

The INR measured at the time of an event was recorded on the same form on which the event was reported. If no INR measurement was available at the time of the event, the most recent measurement obtained within the preceding 28 days was used.

\section{Calculation of Observation Times for Different INR Levels}

The total time each patient was observed was tabulated from the patient's entry into the study until the final visit in April 1993, the occurrence of an event, or 28 days after the discontinuation of anticoagulant therapy, whichever came first. This observation time was stratified according to INR level. Half the time from one INR measurement to the previous measurement and half the time to the subsequent measurement were assigned as the period when that INR measurement was in effect. ${ }^{15}$ When more than 56 days passed between INR measurements for a patient, no more than 28 days of that period could be assigned to each measurement; the intervening days, for which the intensity of anticoagulation was undefined, were assigned to a separate category known as "unknown INR."

\section{Statistical Analysis}

Event rates, 95 percent confidence intervals, and event-rate ratios were derived by standard calculations, based on the assumption of a Poisson distribution of the number of events, with an Egret statistical package. ${ }^{16}$ A multivariate Poisson regression model ${ }^{17}$ was used to control for confounding due to possible differences in age, systolic blood pressure, history of ischemic heart disease, and the presence of an enlarged heart (cardiothoracic ratio, $>50$ percent) as seen on chest radiography. These variables have been identified as the most important predictors of recurrent cardiovascular events in patients treated with oral anticoagulants (unpublished data). In addition, other studies have identified age and systolic blood pressure as predictors of bleeding complications. ${ }^{18}$

\section{RESULTS}

From October 1988 through May 1992, 1007 patients were enrolled in the European Atrial Fibrillation Trial. Of 669 patients eligible for anticoagulant therapy, 225 were randomly assigned to treatment with oral anticoagulants. Two patients refused to begin treatment with anticoagulants, and treatment was stopped within seven days in one patient because of erratic compliance. In another eight patients no INR values were obtained, because before their first follow-up visit they either had a major outcome event or discontinued anticoagulant treatment (four patients each). These 11 patients were excluded from further analysis. For the remaining 214 patients, a total of 72 patient-years spent receiving the treatment were unaccounted for because there was insufficient information on INR measurements. The analyses reported here were based on the remaining 377 patient-years. Fifty-five percent of the patients were men, their mean age was 71 years, and 43 percent had a history of hypertension.

\section{Intensity of Anticoagulation}

A total of 4883 INR values were reported to the study office, with a median of 21 determinations per patient (range, 1 to 63). Given an average follow-up of 2.1 years while the patients were receiving treatment, INR determinations were reported approximately every 5 weeks. INR values for 47 patients were unavailable at some time during the trial for periods exceeding three months, indicating that for these patients only assumptions can be made about the overall intensity of anticoagulation. Figure 1 shows the intensity of anticoagulation that was obtained. Fifty-six percent of all available INR measurements were within the target range of 2.5 to 3.9. Thirty-five percent of the measurements were below this range, and 9 percent were above it. These percentages were similar for all age groups studied (under 65 years, from 65 through 75 years, and over 75 years).

\section{INR-Specific Event Rates}

An overview of all events is given in Table 1 , and the corresponding INR-specific event rates are shown in Table 2. Higher INR levels were associated with increases in the incidence of not only major bleeding complications, but also presumed ischemic events, indicating that the latter could theoretically have included unrecognized hemorrhagic events (e.g., in the five sudden deaths and the three strokes in patients for whom no CT scans were performed). Because of the relatively small number of events, further analyses were restricted to the 39 outcome events characterized 
by an ischemic episode (in 23 patients), a major hemorrhagic episode (in 13), or an undetermined episode (in 3), whichever came first.

For these 39 combined events, the total number of patient-years included within the INR-specific intervals was as follows: 40 patient-years for INRs of less than 2.0, 186 years for INRs from 2.0 to 2.9, 114 years for INRs from 3.0 to $3.9,27$ years for INRs from 4.0 to 4.9 , and 10 years for INRs of 5.0 or more. For 32 of the 39 outcome events, INR measurements obtained at the time of the event were available. INR-specific incidence rates and the corresponding 95 percent confidence intervals are shown in Figure 2. The highest event rates corresponded to INR values below 2.0 (predominantly ischemic events; rate, 18 per 100 patient-years) and above 5.0 (predominantly hemorrhagic events; rate, 60 per 100 patient-years). The lowest incidence rate for ischemic and hemorrhagic events combined was found at INRs from 2.0 to 3.9. Multivariate Poisson regression analyses were performed to assess the independent risk of an outcome event for INR-specific intervals, after control for age, systolic blood pressure at entry into the study, history of ischemic cardiac disease, and cardiomegaly (Table 3 ).

As compared with therapy producing an INR below 2.0, anticoagulant therapy producing an INR from 2.0 to 2.9 reduced the incidence of events by 80 percent (rate ratio, 0.2; 95 percent confidence interval, 0.1 to $0.6)$. This effect was slightly less in the case of therapy producing an INR from 3.0 to 3.9 (rate ratio, 0.4; 95 percent confidence interval, 0.1 to 1.1). At higher intensities the event rate was increased, largely because of an increased rate of hemorrhagic complications (Fig. 2). With INRs from 4.0 to 4.9 , the rate ratio for vascular events and major hemorrhages was 1.6 (95 percent
Table 1. First Ischemic and Hemorrhagic Events Occurring among the 214 Study Patients.

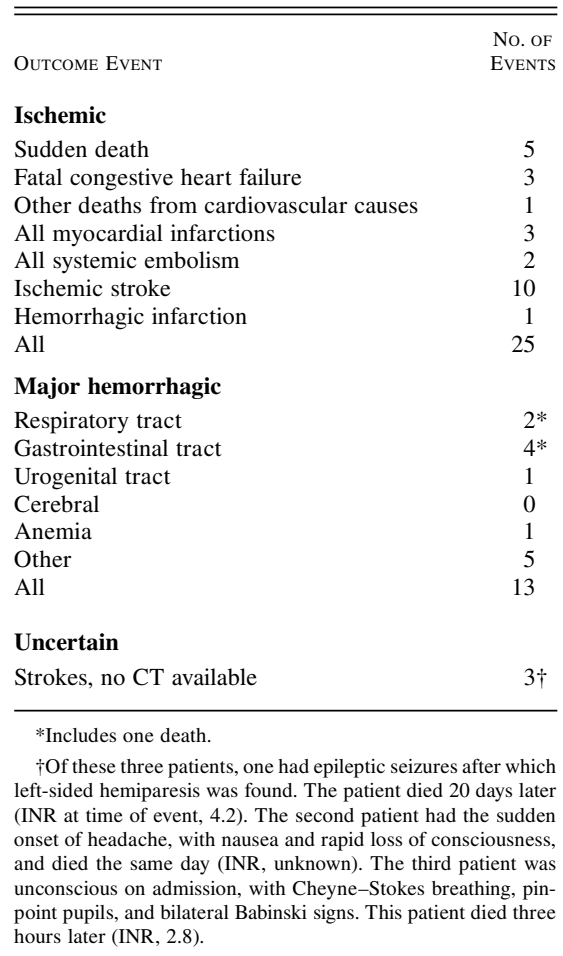

confidence interval, 0.6 to 4.6), and with INRs of 5.0 or above this rate ratio increased even further, to 3.6 (95 percent confidence interval, 1.2 to 11 ). In these analyses both age and the presence of cardiomegaly remained important risk factors for recurrent events (thromboembolic or hemorrhagic). Additional analyses

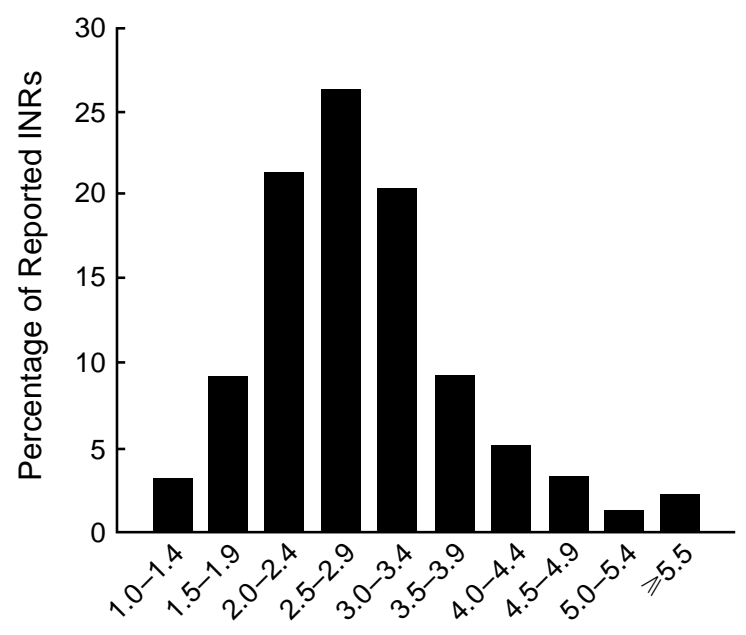

INR Range

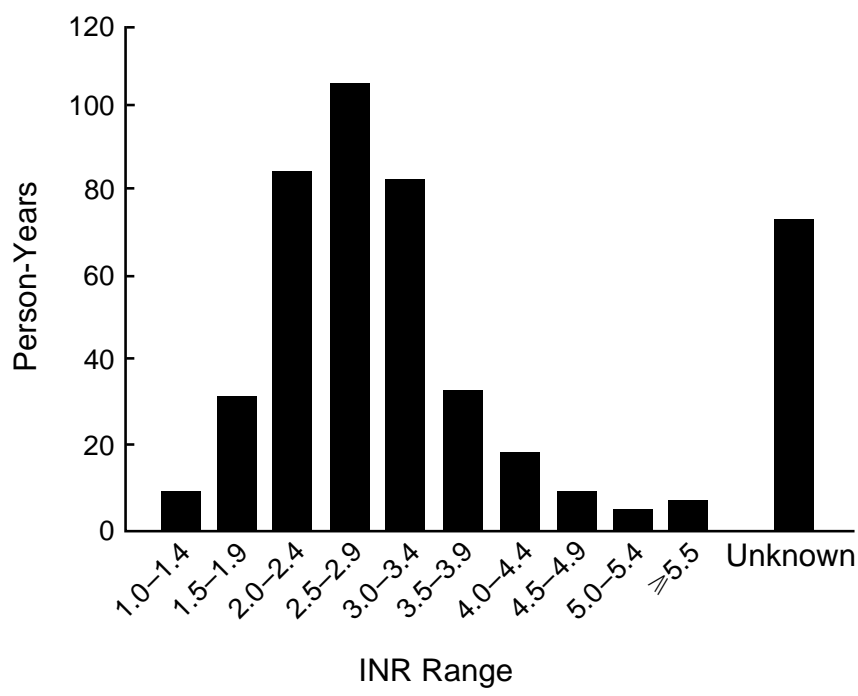

Figure 1. Intensity of Anticoagulation in the Study Patients, According to Reported INR Values and Person-Years of Exposure to Various Levels of Anticoagulant Therapy.

The left-hand panel shows the percentage of all reported INRs that were within the given ranges. The right-hand panel shows the number of person-years that were associated with each INR range. If more than 56 days passed between consecutive INR measurements, 28 days were assigned to each measurement and the INR value of the remaining days was considered to be unknown. 
Table 2. First Ischemic and Hemorrhagic Complications among the Study Patients, According to the INR at the Time of the Event.*

\begin{tabular}{|c|c|c|c|c|c|c|c|}
\hline \multirow[t]{3}{*}{ INR } & \multirow[t]{3}{*}{$\begin{array}{l}\text { PERSON-YR OF } \\
\text { EXPOSURE }\end{array}$} & \multicolumn{2}{|c|}{ ISCHEMIC EVENTS } & \multicolumn{2}{|c|}{ MAJOR BLEEDING } & \multicolumn{2}{|c|}{ Either Event } \\
\hline & & & No./100 & & No./100 & & No./100 \\
\hline & & NO. & PERSON-YR & No. & PERSON-YR & No. & PERSON-YR \\
\hline Unknown & 72 & $4(2)$ & 7 & 2 & 3 & $7(3) \dagger$ & 10 \\
\hline$<2.0$ & 40 & $7(2)$ & 18 & 0 & 0 & $7(2)$ & 18 \\
\hline 2.0 to 2.9 & 186 & $3(2)$ & 2 & 2 & 1 & $6(3) \dagger$ & 3 \\
\hline 3.0 to 3.9 & 114 & $4(2)$ & 4 & $3(1)$ & 3 & $7(3)$ & 7 \\
\hline 4.0 to 4.9 & 27 & $6(1)$ & 26 & 1 & 4 & $8(2) \dagger$ & 30 \\
\hline$\geqslant 5.0$ & 10 & 1 & 10 & $5(1)$ & 50 & $6(1)$ & 60 \\
\hline $\begin{array}{l}\text { All with known } \\
\text { INR }\end{array}$ & 377 & $21(7)$ & 6 & $11(2)$ & 3 & 34 (12) & 9 \\
\hline
\end{tabular}

*Numbers in parentheses are numbers of fatal events.

$\dagger$ Includes one patient with stroke of uncertain cause.

showed that an age over 75 years was associated with a higher risk of major bleeding (rate ratio, 3.6; 95 percent confidence interval, 1.0 to 13) independently of the therapeutic intensity of anticoagulation. Systolic blood pressure over $160 \mathrm{~mm} \mathrm{Hg}$ at study entry was not associated with a higher rate of major bleeding complications.

\section{Discussion}

In our study of patients with nonrheumatic atrial fibrillation and recent cerebral ischemia, anticoagulation resulting in an INR of 2.0 to 3.9 offered the best balance between recurrent ischemic events and major bleeding complications. It therefore seems that anticoagulation with a target intensity resulting in an INR of 3.0 may provide an optimal therapeutic effect with the lowest risk of bleeding. These findings are in agreement with guidelines formulated in recent studies ${ }^{19}$ and the guidelines of the American College of Chest Phy-

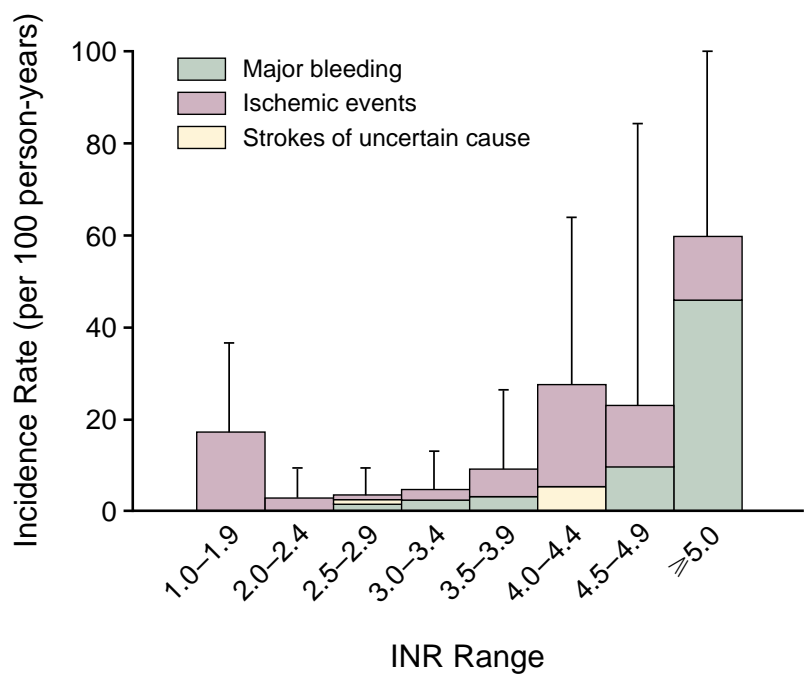

Figure 2. INR-Specific Incidence Rates for the Occurrence of a First Ischemic or Hemorrhagic Complication in the Study Patients.

$\mathrm{T}$ bars indicate 95 percent confidence intervals. sicians, ${ }^{20,21}$ but they may suggest a slightly lower intensity of anticoagulation than was recommended in the Dutch guidelines for high-risk patients (target INR, 3.5; range, 3.0 to 4.5)..$^{22}$ Because of the limited number of observations, the present study contains insufficient evidence to refute the Dutch guidelines. Therefore, future studies of the optimal intensity of anticoagulation in other populations of patients are needed to settle the issue definitively. Two ongoing primary-prevention studies, the Primary Prevention of Arterial Thromboembolic Processes in Atrial Fibrillation Study (PATAF) and the second Atrial Fibrillation, Aspirin, Anticoagulant Study (AFASAK II), are comparing various targets of anticoagulation. Until the results of these studies are available, one should use caution in extrapolating our results to primary prevention.

The analyses of efficacy presented here can provide clinicians with helpful insights, but they should not replace intention-to-treat analyses. The effect of erratic compliance with anticoagulation therapy can be assessed by this method, but the effects of withdrawal from anticoagulant treatment for reasons other than major bleeding complications (e.g., recurrent minor bleeding and reluctance by the patient to adhere to stringent regimens in which prothrombin time is controlled) are lost in such an analysis. Intention-to-treat analyses allow more general conclusions with regard to the strategy of prescribing anticoagulants, regardless of the intensity of coagulation attained, which, even with intensive control in the laboratory, depends largely on characteristics of the patient that are not always easily defined or recognized. ${ }^{23}$

In our study, the incidence of major bleeding complications related to oral anticoagulant therapy was 2.8 per 100 patient-years, slightly higher than in the primary-prevention studies of patients with nonrheumatic atrial fibrillation but within the ranges reported by other studies that considered a wider range of indications. ${ }^{15,24,25}$ Differences in the intensity of anticoagulation may explain this difference in part, but the higher mean age of our patients may also have influenced the findings. The relation between higher age and an increased risk of major hemorrhagic events is still controversial, ${ }^{26-28}$ but it seems plausible to expect a higher risk of complications because of an increase in coexisting conditions. This theory is supported by the findings of the recently completed second study by the Stroke Prevention in Atrial Fibrillation (SPAF II) investigators. ${ }^{29}$ In our study population, no association was found between high systolic blood pressure or a history of hypertension, on the one hand, and the risk of bleeding on the other. ${ }^{24,28,30}$ Possible explanations may be that the study sample was small, that only patients with ad- 
Table 3. Multivariate Analysis of the Ischemic and Hemorrhagic Complications That Occurred First in the Study Patients.

\begin{tabular}{|c|c|c|}
\hline VARIABLE & $\begin{array}{l}\text { Adjusted Rate Ratio } \\
\text { (95\% CI*) }\end{array}$ & P VAlue \\
\hline \multicolumn{3}{|l|}{ INR } \\
\hline$<2.0$ & 1.0 & \\
\hline 2.0 to 2.9 & $0.2(0.1-0.6)$ & 0.003 \\
\hline 3.0 to 3.9 & $0.4(0.1-1.1)$ & 0.075 \\
\hline 4.0 to 4.9 & $1.6(0.6-4.6)$ & 0.378 \\
\hline$\geqslant 5.0$ & $3.6(1.2-11)$ & 0.022 \\
\hline \multicolumn{3}{|l|}{ Age $-\mathrm{yr}$} \\
\hline$\leqslant 75$ & 1.0 & 0.002 \\
\hline$>75$ & $3.1(1.5-6.4)$ & \\
\hline \multicolumn{3}{|c|}{$\begin{array}{c}\text { Systolic blood pressure at } \\
\text { entry - } \mathrm{mm} \mathrm{Hg}\end{array}$} \\
\hline$\leqslant 160$ & 1.0 & 0.325 \\
\hline$>160$ & $1.6(0.6-3.9)$ & \\
\hline \multicolumn{3}{|c|}{$\begin{array}{l}\text { History of ischemic heart } \\
\text { disease }\end{array}$} \\
\hline No & 1.0 & 0.431 \\
\hline Yes & $1.4(0.6-3.4)$ & \\
\hline \multicolumn{3}{|c|}{ Cardiothoracic ratio $>50 \%$} \\
\hline No & 1.0 & 0.003 \\
\hline Yes & $2.9(1.4-5.9)$ & \\
\hline
\end{tabular}

*CI denotes confidence interval.

equately controlled hypertension were enrolled, and that the blood-pressure measurements obtained at study entry that were used in this analysis were probably unrepresentative of systolic blood pressures during the rest of the study period.

In conclusion, the optimal therapeutic range for anticoagulation in the secondary prevention of vascular events in relatively old patients with nonrheumatic atrial fibrillation who have recently had a minor cerebral ischemic event lies between INRs from 2.0 to 3.9, with a target INR of 3.0. When the INR is above 5.0, the risk of serious bleeding complications becomes unacceptable, whereas no apparent reduction in thromboembolic events was observed at INRs below 2.0.

We are indebted to Prof. E.A. Loeliger for his valuable advice and comments.

\section{APPENDix}

The following centers and investigators participated in the European Atrial Fibrillation Trial. The number of patients randomized at each center is given in parentheses.

Belgium: Bruges - I. Dehaene, M. D'Hooghe, M. Marchau, and M. van Zandijcke (3); Brussels - C. Delwaide, A. Depré, and E.C. Laterre (3); Dendermonde - E. van Buggenhout (5); Geel - J. Schurmans, E. de Smet, and L. Swerts (4); Ghent - G. van den Abeele (4); Leuven - H. Carton and P.M.A. Verdru (8); Mons - P.A. Indekeu and D. Lam (13); Turnhout - V. van den Bergh and L. Mol (1); and Wilrijk - W. van Landegem and T. Strauven (2). Denmark: Copenhagen - G. Boysen, J. Gyring, P. Petersen, and P. Würtzen-Nielsen (11). France: Besançon — T. Crepin-Leblond and T. Moulin (12); Bordeaux - S. Auriacombe and J.M. Orgogozo (2); Bourg-en-Bresse J. Boulliat (36); Brest - J.-Y. Goas and Y. Mocquard (5); Grenoble G. Besson and M. Hommel (5); Lille - C. Adnet-Bonte, E. Josien, and H. Petit (2); Meaux - F. Chedru (5); Paris, Salpêtrière S. Evrard and M. Levasseur (2); Paris, Raymond Garcin - J.L. Mas, O. Meyniard, and M. Zuber (7); Paris, Saint Antoine - P. Amarenco, M.G. Bousser, and E. Roullet (2); Rennes - J.F. Pinel (5); Rouen E. Massardier and B. Mihout (2); Toulouse, Purpan - F. Chollet and A. Rascol (1); and Tours - A. Autret and D. Saundeau (5). Germany: Bochum - T. Büttner and W. Niemczyk (1); Giessen - K.D.
Böhm and C. Hornig (3); Heidelberg - W. Hacke, C. Heiss, and R. Reuther (1); Homburg (Saar) - A. Haaß and M. Stoll (2); Mainz - G. Krämer and G. Rothacher (10); Minden - M. Bauer, O. Busse, S. Koch-Rose, and B. Mueffelmann (13); Tübingen - J. Dichgans and C. Thomas (2); and Wuppertal - O.A.D. Hennen, J. Jörg, H. Schwan, and R. Siepen (3). Israel: Tel Aviv - N.M. Bornstein (15). Italy: Ancona - B. Censori, M. Ceravolo, and L. Provinciali (7); Aosta G. D'Alessandro, E. Bottacchi, L. Carenini, and E. Duc (8); Bari - F. Federico, A. Fiore, P. Lamberti, and P. Lattanzi (11); Bergamo - M. Camerlingo, L. Casto, and A. Mamoli (11); Citta della Pieve G. Bénemìo, F. Boldrini, C. Gatteschi, G. Schillaci, P. Verdecchia, and E. Vignai (8); Citta di Castello - G. Arcelli, S. Bravi, L. Coli, L. Girelli, and A. Purro (9); Como - C. Del Favero, M. Guidotti, G. Pellegrini, M. Santarone, and G. Tadeo (32); Milan, Niguarda G. Bottini, G. Canepari, and R. Sterzi (3); Milan, Policlinico A. Binda, L. Candelise, F. Nador, G. Pinardi, and L. Oliva (9); Parma - A. Mombelloni, O. Ponari, and M. Squeri (11); Pavia - F. Barzizza, A. Cavallini, G. Micieli, G. Nappi, and I. Richichi (7); Perugia, San Sisto - P. Caselli and E. Moretti (3); Perugia - G. Aisa, E. Boschetti, N. Caputo, M.G. Celani, A. Del Favero, G. Nenci, S. Ricci, E. Righetti, and U. Senin (18); Poggibonsi - M. Biotti, M. D'Ettore, and G. Fabrizi (9); Spoleto - S. Grasselli and F. Pezzella (6); Trieste - L. Antonutti, F. Chiodo Grandi, D. Guerrini, A. Marzalli, B. Pinamonti, R. Salvi, and C. Sammartini (33); and Vicenza P. Dudine, F. Ferro Milone, and M. Vicenzi (4). The Netherlands: Almelo - J.W.M. ter Berg, H.J. Gelmers, J.A. Haas, and S.F. Lindeboom (8); Amsterdam, Academic Medical Center — D. Herderschêe, A. Hijdra, and M. Vermeulen (3); Amsterdam, Free University - F.W. Bertelsmann, G. J. Hazenberg, and J.C. Koetsier (10); Bergen op Zoom - P.J.I.M. Berntsen, T.B. Gebbink, and F.M. Sleegers (6); Deventer - J.A. van Beeck, W.J. Feikema, J.H.M. van Gasteren, A.N. Veltema, and C.J.M. Vredeveld (1); Dordrecht - P.A.T. Carbaat, L.I. Hertzberger, and R.P. Kleyweg (12); Goes - A.M. Boon, W.H.G. Lieuwens, and F. Visscher (13); The Hague - W.F.M. Arts, A. Boon, L.C.M. Moll, W.V.M. Perquin, J.T.J. Tans, R. Tonk, and A.W. de Weerd (10); Groningen - H. Haaxma-Reiche, H. J.G.H. Oosterhuis, and J.W. Snoek (3); Heerlen - C.L. Franke, J.F. Mirandolle, and P.J.J. Koehler (27); Leiden - P.E. Briët and J. van Rossum (5); Maastricht - J. Boiten, A.E. Boon, J. Lodder, and J. Nihom (15); Nieuwegein H.W. Mauser (2); Nijmegen - C.W.G.M. Frenken, E.F.J. Poels, M.J.J. Prick, and W.I.M. Verhagen (12); Rotterdam, Dijkzigt - W.J.J.F. Hoppenbrouwers, P. J. Koudstaal, and A. Staal (27); Rotterdam, Fransiscus - P.R. Beneder, C. Bulens, and L.H. Penning de Vries-Bos (5); Tilburg - A.A.W. Op de Coul, A.G.M. Leyten, C.C. Tijssen, and R.L.L.A. Schellens (9); Utrecht - J.P.M. Gillessen, J. van Gijn, and L. J. Kappelle (14); and Vlaardingen - J.J.M. Driesen, W.F. van Oudenaarden, and J.C.B. Verhey (6). Norway: Alesund - O.J. Frisvold, T. Hole, and O.R. Skogen (10); Arendal - B. Aslaksen, F. Gallefoss, and K.O. Laake (5); Bodo - L.K. Berg (1); Drammen - S. Balsliemke and S. Ritland (8); Levanger - K. Hveem (2); Namsos O. Dehli (1); Oslo — U. Abildgaard and T. Dahl (13); and Skien B. Welund (1). Portugal: Coimbra, Centro Hospitalar - J.A. Grilo Gonçalves and J.F. Palmeiro (29); Coimbra, University - R. Amaral, C. Machado, A. Mestre, F. Ribeiro, and L. Sousa (3); Lisbon, Santa Cruz - A. Vasco Salgado (4); Lisbon, San José- A. Baptista, J.M. Candido, A.V. Morgado, and I.M.V. Ramires (41); Lisbon, Santa Maria - M. Crespo, J.M. Ferro, A.S. Franco, T.M.P. Melo, and V. Oliveira (39); and Porto - A.F. Bastos Lima, M.M. Correia, J.C. Lopez, R. Morgado, and M. Santos (21). Spain: Alcoy-Alicante - G. Grau, J. Lopez, R. Martin, and J. Matias-Guiu (11); Barcelona, Bellvitge J. Alio, M. Calopa, F. Miralles, and F. Rubio (4); Barcelona, del Mar - J. Fueyo, C. Gomez, L. Molina, L. D’Olhaberriague, and L. SolerSingla (11); Gerona - A. Dávalos, D. Genís, and J. Bassaganyas (9); Madrid - P. Barreiro, E. Diez-Tejedor, and A. Frank (8); Tarragona - J. Costa and R. Marés (3); and Valencia - L. Lainez and J. Sancho (10). Sweden: Örebro - K.H. Hennerdal, N. Rudback, M. Samuelsson, and P. Sigfridson (9); and Sundsvall - M. Hedenus (11). Switzerland: Lausanne - J. Bogousslavsky, J. Ghika, L. Mariani, B. Nater, and F. Schmid (27). United Kingdom: Aberdeen, Royal R. Knight (1); Aberdeen, Woodend - S. J.C. Hamilton and J. Kane (5); Amersham - R. Bell and C.K. Foote (4); Edinburgh, City - T. Cassidy and C.S. Gray (9); Edinburgh, Western - P.A.G. Sandercock, R. Sellar, 
and C.P. Warlow (16); Keighley - J.G. Howe (4); King's Lynn - J.C. McGourty (2); Leeds - J. Bamford and M. Johnson (28); Leicester G.M. Castleden, G.D. Harper, B.N. Panayiotou, and T. Robinson (7); Liverpool, Royal - D. Barer (19); Liverpool, Walton - P. Humphrey (2); London - K. Kafetz and G. McElligott (6); Newcastle - D. Bates and N.E.F. Cartlidge (1); Sheffeld - G.S. Venables (49); and Wimbledon - P. Monro (1).

\section{REFERENGES}

1. The Boston Area Anticoagulation Trial for Atrial Fibrillation Investigators. The effect of low-dose warfarin on the risk of stroke in patients with nonrheumatic atrial fibrillation. N Engl J Med 1990;323:1505-11.

2. Connolly SJ, Laupacis A, Gent M, Roberts RS, Cairns JA, Joyner C. Canadian Atrial Fibrillation Anticoagulation (CAFA) Study. J Am Coll Cardiol 1991;18:349-55.

3. Ezekowitz MD, Bridgers SL, James KE, et al. Warfarin in the prevention of stroke associated with nonrheumatic atrial fibrillation. N Engl J Med 1992; 327:1406-12. [Erratum, N Engl J Med 1993;328:148.]

4. Petersen P, Boysen G, Godtfredsen J, Andersen ED, Andersen B. Placebocontrolled, randomised trial of warfarin and aspirin for prevention of thromboembolic complications in chronic atrial fibrillation: the Copenhagen AFASAK study. Lancet 1989;1:175-9.

5. Stroke Prevention in Atrial Fibrillation Investigators. Preliminary report of the Stroke Prevention in Atrial Fibrillation Study. N Engl J Med 1990;322: 863-8.

6. Idem. Stroke Prevention in Atrial Fibrillation Study: final results. Circulation 1991;84:527-39.

7. EAFT (European Atrial Fibrillation Trial) Study Group. Secondary prevention in non-rheumatic atrial fibrillation after transient ischaemic attack or minor stroke. Lancet 1993;342:1255-62.

8. Bussey HI, Force RW, Bianco TM, Leonard AD. Reliance on prothrombin time ratios causes significant errors in anticoagulation therapy. Arch Intern Med 1992;152:278-82

9. Bussey HI. Aspirin and prevention of stroke. Lancet 1994;343:234-5.

10. Rosendaal FR, Cannegieter SC, van der Meer FJM, Briët E. A method to determine the optimal intensity of oral anticoagulant therapy. Thromb Haemost 1993;69:236-9.

11. Kirkwood TBL. Calibration of reference thromboplastins and standardisation of the prothrombin time ratio. Thromb Haemost 1983;49:238-44.

12. International Committee for Standardization in Haematology, International Committee on Thrombosis and Haemostasis. ICSH/ICTH recommendations for reporting prothrombin time in oral anticoagulant control. Thromb Haemost 1985;53:155-6.
13. Loeliger EA. Laboratory control, optimal therapeutic ranges and therapeutic quality control in oral anticoagulation. Acta Haematol 1985;74:125-31.

14. Poller L. Therapeutic ranges in anticoagulant administration. BMJ 1985; 290:1683-6

15. van der Meer FJM, Rosendaal FR, Vandenbroucke JP, Briët E. Bleeding complications in oral anticoagulant therapy: an analysis of risk factors. Arch Intern Med 1993;153:1557-62.

16. Egret statistical package. Seattle: Statistics and Epidemiology Research Corporation, 1990 (package insert).

17. Frome EL. The analysis of rates using Poisson regression models. Biometrics 1983;39:665-74.

18. Levine MN, Hirsh J, Landefeld S, Raskob G. Hemorrhagic complications of anticoagulant treatment. Chest 1992;102:Suppl:352S-363S

19. Albers GW. Atrial fibrillation and stroke: three new studies, three remaining questions. Arch Intern Med 1994;154:1443-8.

20. Hirsh J, Dalen JE, Deykin D, Poller L. Oral anticoagulants: mechanism of action, clinical effectiveness, and optimal therapeutic range. Chest 1992; 102:Suppl:312S-326S

21. Laupacis A, Albers G, Dunn M, Feinberg W. Antithrombotic therapy in atrial fibrillation. Chest 1992;102:Suppl:426S-433S.

22. Loeliger EA. Therapeutic target values in oral anticoagulation - justification of Dutch policy and a warning against the so-called moderate-intensity regimens. Ann Hematol 1992;64:60-5. [Erratum, Ann Hematol 1992;64: 253.]

23. Schwartz D, Lellouch J. Explanatory and pragmatic attitudes in therapeutical trials. J Chronic Dis 1967;20:637-48.

24. Levine M, Hirsh J. Hemorrhagic complications of long-term anticoagulant therapy for ischemic cerebral vascular disease. Stroke 1986;17:111-6.

25. Lundström T, Rydén L. Haemorrhagic and thromboembolic complications in patients with atrial fibrillation on anticoagulant prophylaxis. J Intern Med $1989 ; 225: 137-42$

26. Gurwitz JH, Goldberg RJ, Holden A, Knapic N, Ansell J. Age-related risks of long-term oral anticoagulant therapy. Arch Intern Med 1988;148:1733-6.

27. Landefeld CS, Beyth RU. Anticoagulant-related bleeding: clinical epidemiology, prediction, and prevention. Am J Med 1993;95:315-28.

28. Launbjerg J, Egeblad H, Heaf J, Nielsen NH, Fugleholm AM, Ladefoged K. Bleeding complications to oral anticoagulant therapy: multivariate analysis of 1010 treatment years in 551 outpatients. J Intern Med 1991;229:351-

29. Stroke Prevention in Atrial Fibrillation Investigators. Warfarin versus aspirin for prevention of thromboembolism in atrial fibrillation: Stroke Prevention in Atrial Fibrillation II Study. Lancet 1994;343:687-91.

30. Wintzen AR, de Jonge H, Loeliger EA, Bots GTAM. The risk of intracerebral hemorrhage during oral anticoagulant treatment: a population study. Ann Neurol 1984;16:553-8.

\section{Massachusetts Medical Society \\ Registry on Continuing Medical Education}

To obtain information on continuing medical education courses in the New England area, call between 9:00 a.m. and 12:00 noon, Monday through Friday, (617) 893-4610 or in Massachusetts 1-800-322-2303, ext. 1342. 